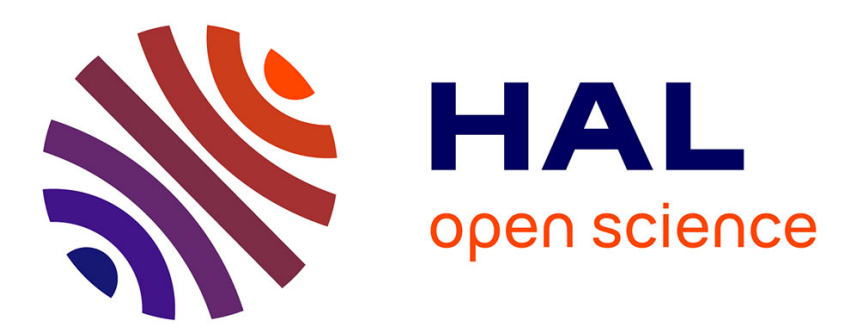

\title{
Stability of charge ordering in La0.5-xHoxCa0.5MnO3 polycrystalline manganites
}

S. Dhieb, A. Krichene, F. Fettar, N. Chniba Boudjada, W. Boujelben

\section{To cite this version:}

S. Dhieb, A. Krichene, F. Fettar, N. Chniba Boudjada, W. Boujelben. Stability of charge ordering in La0.5-xHoxCa0.5MnO3 polycrystalline manganites. Applied physics. A, Materials science \& processing, 2021, 127 (9), pp.700. 10.1007/s00339-021-04848-4 . hal-03379841

\section{HAL Id: hal-03379841 \\ https://hal.science/hal-03379841}

Submitted on 4 Nov 2021

HAL is a multi-disciplinary open access archive for the deposit and dissemination of scientific research documents, whether they are published or not. The documents may come from teaching and research institutions in France or abroad, or from public or private research centers.
L'archive ouverte pluridisciplinaire HAL, est destinée au dépôt et à la diffusion de documents scientifiques de niveau recherche, publiés ou non, émanant des établissements d'enseignement et de recherche français ou étrangers, des laboratoires publics ou privés. 


\title{
Stability of charge ordering in $\mathrm{La}_{0.5-\mathrm{x}} \mathrm{Ho}_{\mathrm{x}} \mathrm{Ca} \mathrm{a}_{0.5} \mathrm{MnO}_{3}$ polycrystalline manganites
}

S. Dhieb ${ }^{1}$, A. Krichene ${ }^{1, *}$, F. Fettar ${ }^{2}$, N. Chniba Boudjada ${ }^{1,2}$, W. Boujelben ${ }^{1}$

${ }^{1}$ Laboratoire de Physique des Matériaux, Faculté des Sciences de Sfax, Université de Sfax, B.P. 1171, 3000 Sfax, Tunisia.

${ }^{2}$ Université Grenoble Alpes, CNRS, Grenoble INP, Institut Néel, 38000 Grenoble, France.

\begin{abstract}
Magnetotransport properties of $\mathrm{La}_{0.5-\mathrm{x}} \mathrm{Ho}_{\mathrm{x}} \mathrm{Ca}_{0.5} \mathrm{MnO}_{3}(\mathrm{x}=0.05$ and 0.1 ) polycrystalline samples were investigated in order to study the effect of magnetic $\mathrm{Ho}^{3+}$ ions on the stability of the charge ordering (CO) and magnetic phase coexistence in pristine $\mathrm{La}_{0.5} \mathrm{Ca}_{0.5} \mathrm{MnO}_{3}$. Our samples were synthesized by using sol-gel method. Temperature dependence of resistivity shows an insulating behavior with high resistivity values, confirming the presence of long-range CO. The application of $7 \mathrm{~T}$ magnetic field slightly reduces resistivity values and demonstrates relatively small magnetoresistance (MR) values (-MR(T) did not exceed $14 \%$ under $7 \mathrm{~T}$ applied field). This observation indicates that the CO in the Ho-based specimens is strong, which indicates that Ho-substitution for $\mathrm{La}$ in $\mathrm{La}_{0.5} \mathrm{Ca}_{0.5} \mathrm{MnO}_{3}$ gives more strength to the $\mathrm{CO}$.
\end{abstract}

Keywords: Half-doped manganite; Magnetotransport; Magnetoresistance; Charge ordering.

${ }^{*}$ Corresponding author:

Dr Akram Krichene.

Phone: +21694948998＜noBreak>E-mail: akramkri@hotmail.fr

Orcid ID: 0000-0002-3539-5976 


\section{Introduction}

Half-doped manganites generally exhibit outstanding properties like magnetoresistance (MR), charge ordering (CO) and magnetic phase separation. Such phenomena can give birth to potential technological applications like spintronics, high density data storage and spin valves [1-5]. These materials with the general formula $\mathrm{R}_{0.5} \mathrm{~A}_{0.5} \mathrm{MnO}_{3}$ (where $\mathrm{R}$ is a lanthanide and $\mathrm{A}$ is an alkaline earth) are still investigated due to their remarkable physical behavior [1-10]. $\mathrm{La}_{0.5} \mathrm{Ca}_{0.5} \mathrm{MnO}_{3}$ is one of the most studied half-doped manganites [2-6, 11, 12]. This sample is characterized by a CE-type antiferromagnetic (AFM) configuration with the presence of CO state at low temperatures. When heated, this compound exhibits a first magnetic phase transition from a CO-AFM to a ferromagnetic state around $\mathrm{CO}$ temperature $\mathrm{T}_{\mathrm{CO}}=150 \mathrm{~K}$, followed by a transformation to the paramagnetic (PM) phase around curie temperature $\mathrm{T}_{\mathrm{C}}=220 \mathrm{~K}[11,12]$. Below $\mathrm{T}_{\mathrm{CO}}$, the system is defined as a mixture of both CO-AFM and ferromagnetic domains, testifying the magnetic phase separation phenomenon. The CO state is generally observed phenomenon in half-doped manganites such as $\mathrm{La}_{0.5} \mathrm{Ca}_{0.5} \mathrm{MnO}_{3}[1-4,11-15]$. This phenomenon is characterized by a real space ordering of the $\mathrm{Mn}^{3+}$ and $\mathrm{Mn}^{4+}$ species, which is accompanied by the orbital ordering, originating from Jahn-Teller distortion. The establishment of the CEtype CO state at low temperature changes the structure of orthorhombic to monoclinic symmetry which gives rise to an insulating ground state. The insulating CO can be significantly affected by the application of an external magnetic field, temperature, substituent nature and strain $[2,4,10,12-15]$.

The partial substitution of lanthanum by other rare earths elements (Ho, Dy, Eu, Sm...) in half-doped $\mathrm{La}_{0.5} \mathrm{Ca}_{0.5} \mathrm{MnO}_{3}$ gives birth to fascinating and unusual dielectric, magnetic and electrical properties like colossal magnetodielectric effect, colossal magnetoresistance, Griffiths phase, magnetic phase separation, training effect and kinetic arrest [6, 12, 16-25]. In a previous work, we have investigated the effect of A-site holmium substitution on the structural and magnetic properties of $\mathrm{La}_{0.5-\mathrm{x}} \mathrm{Ho}_{\mathrm{x}} \mathrm{Ca}_{0.5} \mathrm{MnO}_{3}(0 \leq \mathrm{x} \leq 0.15)$ samples [6]. The study revealed that the increasing of the holmium content results in a drastic change in the structural and magnetic properties, leading to the weakening of ferromagnetic interactions. The Ho substitution for La strengthens CO state and converts its nature from AFM to PM. In this communication, we have tried to study the magnetotransport properties in $\mathrm{La}_{0.5-\mathrm{x}} \mathrm{Ho}_{\mathrm{x}} \mathrm{Ca}_{0.5} \mathrm{MnO}_{3}$ samples with $\mathrm{x}=0.05$ and 0.1 . Such study can highlight the effect of holmium substitution on the CO stability and magnetic phase coexistence in the studied system. 


\section{Experimental Procedure}

$\mathrm{La}_{0.5-\mathrm{x}} \mathrm{Ho}_{\mathrm{x}} \mathrm{Ca}_{0.5} \mathrm{MnO}_{3}(\mathrm{x}=0.05$ and 0.1$)$ specimens were prepared by sol-gel technique using high-purity (99.9\%) $\mathrm{La}_{2} \mathrm{O}_{3}, \mathrm{Ho}_{2} \mathrm{O}_{3}, \mathrm{CaCO}_{3}$ and $\mathrm{MnO}_{2}$. The synthesis process was previously described elsewhere [6]. Purity and homogeneity of the samples were confirmed by X-ray powder diffraction (XRD). The structural analysis was carried out by using Fullprof program. The morphology of our samples was studied using a JEOL 840 A Scanning electron microscope (SEM). The average grain size was calculated by the ImageJ software. Resistivity measurements were realized using physical property measurement system (PPMS, Quantum Design), based on a standard four-probe method in the temperature range 115-300 K with applied magnetic field values up to 7T.

\section{Results and discussions}

Fig. 1 displays the Rietveld refined XRD patterns for $\mathrm{La}_{0.5-\mathrm{x}} \mathrm{Ho}_{\mathrm{x}} \mathrm{Ca}_{0.5} \mathrm{MnO}_{3}(\mathrm{x}=0.05$ and 0.1) samples. Refinement results reveal that all our samples crystallize in the orthorhombic structure with Pnma space group and all the structural parameters are listed in table 1 [6]. In order to take into account the intrinsic strain, the Williamson-Hall method can be used to find the crystallite size $\mathrm{D}_{\mathrm{wH}}$ and the microstrain $\varepsilon$ as follows [26]:

$$
\beta_{h k l} \cos \theta=\frac{K \lambda}{D_{W H}}+4 \epsilon \sin \theta(1)
$$

where $\beta_{\mathrm{hkl}}$ is the full width at half of the maximum intensity for hkl planes. From WilliamsonHall plots present on fig. 2, the $\mathrm{D}_{\mathrm{wH}}$ were found to be $89 \mathrm{~nm}$ and $134 \mathrm{~nm}$ for $\mathrm{x}=0.05$ and 0.1 , respectively and the strain distribution values are $2.1810^{-3}$ and $1.9610^{-3}$ for $\mathrm{x}=0.05$ and 0.1 , respectively. One can notice that the microstrain slightly decreases with increasing Ho concentration, due to the important particle size of $x=0.1$ sample, compared to that of $x=0.05$ sample. For a better understanding of holmium contribution on the morphology, we have represented in fig. 3 the SEM micrographs of $\mathrm{La}_{0.5-\mathrm{x}} \mathrm{Ho}_{\mathrm{x}} \mathrm{Ca}_{0.5} \mathrm{MnO}_{3}(\mathrm{x}=0.05,0.10$ and 0.15$)$ samples. It is clear that fig. 3 reveals a heterogeneous morphology characterized by various grain sizes and shapes. The average grains size values are found to be $261 \mathrm{~nm}, 300 \mathrm{~nm}$ and 306 $n m$ for $x=0.05,0.1$ and 0.15 [6], respectively. Porosity seems to be reduced by Ho substitution. Large particles may support the establishment of long-range CO, which promotes its stability. 
In order to investigate the $\mathrm{CO}$ and the magnetotransport properties of the studied samples, the evolution of resistivity as a function of temperature for several values of applied magnetic field for $\mathrm{La}_{0.45} \mathrm{Ho}_{0.05} \mathrm{Ca}_{0.5} \mathrm{MnO}_{3}$ sample is plotted in fig. 4. The lower inset of fig. 4 shows the electrical resistivity for $\mathrm{x}=0.1$ sample as a function of temperature in absence of external magnetic field. The studied samples clearly exhibit an insulating behavior in the whole studied temperature range. The electrical behavior of the two samples is nearly the same. It is believed that further increase of holmium concentration $\mathrm{x}$ will not affect the electrical properties of $\mathrm{La}_{0.5-\mathrm{x}} \mathrm{Ho}_{\mathrm{x}} \mathrm{Ca}_{0.5} \mathrm{MnO}_{3}$ system since $\mathrm{Ho}_{0.5} \mathrm{Ca}_{0.5} \mathrm{MnO}_{3}$ sample exhibits an identical electrical behavior to that of $x=0.05$ sample (insulating behavior in the whole studied temperature range with important resistivity values (around $10^{7} \Omega . \mathrm{cm}$ ) at low temperatures) [27]. Near 125K, resistivity is very high $\left(\approx 10^{7} \Omega . \mathrm{cm}\right)$, testifying the presence of long-range CO. Based on magnetic study and in the absence of applied magnetic field, CO transition is recorded at $\mathrm{T}_{\mathrm{CO}}$ $=164 \mathrm{~K}$ and $240 \mathrm{~K}$ for $\mathrm{x}=0.05$ and 0.1 , respectively [6]. For the $\mathrm{x}=0.15$ samples, $\mathrm{T}_{\mathrm{CO}}$ was found to be $245 \mathrm{~K}$ [6] and it increases up to $280 \mathrm{~K}$ for $\mathrm{x}=0.5$ sample [27]. This fact demonstrates that enhancing Ho concentration favors the development of CO. The application of $7 \mathrm{~T}$ magnetic field slightly reduces resistivity values, which suggests that the long-range $\mathrm{CO}$ is very stable. In the case of $\mathrm{Tb}^{3+}$ doped $\mathrm{La}_{0.5} \mathrm{Ca}_{0.5} \mathrm{MnO}_{3}$, the $0 \mathrm{~T}$ resistivity exhibited an insulating behavior [24]. With further increase in field up to $5 \mathrm{~T}$, the authors observed the occurrence of a metal-insulator transition [24], which is not the case for our studied samples. In the case of $\mathrm{Ca}_{1-\mathrm{x}} \mathrm{Ho}_{\mathrm{x}} \mathrm{MnO}_{3-\delta}$ nanocrystalline powders, small holmium concentration ( $\left.\mathrm{x}=0.1\right)$ reduces resistivity values and induces the appearance of metal-insulator transition for the doped samples [28]. In the present work, one can note the absence of metallicity for the doped samples. This fact can be due to the contribution of Ho ions, which generate a great disorder due to their small size $\left(\mathrm{r}_{\mathrm{Ho}}{ }^{3+}=1.072 \AA\right)$ (compared to $\mathrm{La}^{3+}\left(\mathrm{r}_{\mathrm{La}}{ }^{3+}=1.216 \AA\right)$ ) and important magnetic moment $\left(\approx 10.6 \mu_{\mathrm{B}}\right.$ ). The higher inset of fig. 4 shows the evolution of MR as a function of temperature for $\mathrm{La}_{0.45} \mathrm{Ho}_{0.05} \mathrm{Ca}_{0.5} \mathrm{MnO}_{3}$ sample. MR can be evaluated by following formula:

$$
\operatorname{MR}(\%)=\frac{\rho(H)-\rho(0)}{\rho(0)} \times 100(2)
$$

where $\rho(H)$ is the resistivity measured under $\mu_{0} \mathrm{H}$ applied field and $\rho(0)$ is the resistivity recorded in the absence of magnetic field. Below $225 \mathrm{~K}$, it is clear that the MR is nearly stable, suggesting the presence of spin-dependent scattering process of charge carries at the grain boundaries. In fact, the magnetic field application reduces spin disorder at grain boundaries, which promotes the hopping of $e_{g}$ electrons between grains according to the double exchange 
mechanism. In addition, the MR decreases faster above $225 \mathrm{~K}$, which can be linked to the paramagnetic nature of this sample in this temperature range (the Weiss temperature $\theta_{\mathrm{p}}=224$ $\mathrm{K}$ for $\mathrm{x}=0.05$ sample [6]). It is noteworthy that $-\mathrm{MR}$ values did not exceed $14 \%$ under an applied magnetic field of $7 \mathrm{~T}$, which suggests that the long-range $\mathrm{CO}$ is very strong and requires higher field values to get annihilated.

To get a better understanding of the conduction mechanism, the resistivity behavior can be explained by various theoretical models, like the thermal activation (TA) model, the small polaron hopping (SPH) model and the variable-range hopping (VRH) model. For TA model, the mechanism is given by the following equation:

$$
\rho=\rho_{0} \exp \left(\frac{E_{a}}{k_{B} T}\right)(3)
$$

with $\rho_{0}$ : residual resistivity, $E_{\mathrm{a}}$ : activation energy, $\mathrm{k}_{\mathrm{B}}$ : Boltzmann constant $\left(\mathrm{k}_{\mathrm{B}}=8.617 \mathrm{x} 10^{-5} \mathrm{eV}\right.$. $\mathrm{K}^{-1}$ ) and $\mathrm{T}$ : absolute temperature. The hopping activation energy can be estimated from fig. 5 . The values of $\rho_{0}, \mathrm{E}_{\mathrm{a}}$ and adjusted R-squared factor $\left(\bar{R}^{2}\right)$ are given in table 2. For SPH model, the electrical transport is governed by the polarons hopping to the nearest neighbors due to the strong electron-phonon coupling. This mechanism is described by the following relation:

$$
\rho=\rho_{0} T \exp \left(\frac{E_{a}}{k_{B} T}\right)(4)
$$

The curves related to SPH model are displayed in fig. 5. The phonon frequency according to SPH model can be written as follows:

$$
h v_{p h}=k_{B} \theta_{D}(5)
$$

where $\mathrm{h}$ is the Planck constant $\left(\mathrm{h}=6.62 .10^{-34} \mathrm{~J} . \mathrm{s}\right)$ and $\theta_{\mathrm{D}}$ is the Debye temperature (the SPH model deviates from linearity at $\theta_{\mathrm{D}} / 2$ ). All the fitting parameters for this model are gathered in table 2. It can be seen that the hopping energy, for both TA and SPH models, increases with increasing Ho content. This behavior can indicate an enhancement of the charge carriers localization by Ho substitution, which suggests the stabilization of the CO state. The observed behavior can be also attributed to the reduction of eg electron bandwidth [6]. Besides, the increase in activation energy can be linked to structural and morphological properties of studied samples, i.e., the $\mathrm{x}=0.1$ sample presents higher activation energy compared to $\mathrm{x}=0.05$ one due to the important grain size, shorter bond angle $<\theta_{\mathrm{Mn}-\mathrm{O}-\mathrm{Mn}}>$ and longer bond length. This fact will reduce double exchange mechanism, leading to higher activation energy values. The VRH 
model explains the hopping of a charge carrier from a localized state another which is not necessarily the nearest neighbor. The expression for this model can be written as:

$$
\rho=\rho_{0} \exp \left(\frac{T_{0}}{T}\right)^{0.25}
$$

where $\mathrm{T}_{0}$ is the Mott temperature related to the carrier localization lengthens given by:

$$
T_{0}=\frac{16 \alpha^{3}}{k_{B} N\left(E_{F}\right)}(7)
$$

with $\mathrm{N}\left(\mathrm{E}_{\mathrm{F}}\right)$ : density of states at the Fermi level and $\alpha$ : inverse of the localization length $(\alpha=$ $\left.2.22 \mathrm{~nm}^{-1}[29]\right)$. The $\mathrm{T}_{0}$ values were calculated from the curves plotted in fig. 5 . The fitting results were listed in table 2 . According to fig. 5 , the VRH model gives the best fit due to the perfect match between experimental and simulated curves. This result suggests that this mechanism seems to be the most suitable to describe magnetotransport. The $\mathrm{x}=0.1$ sample presents the largest density of states at the Fermi level, which suggests that hopping distance gets slightly enhanced by increasing Ho content from $\mathrm{x}=0.05$ to $\mathrm{x}=0.1$. For $\mathrm{La}_{0.45} \mathrm{Ho}_{0.05} \mathrm{Ca}_{0.5} \mathrm{MnO}_{3}$ sample, we have tried to evaluate the values of $\mathrm{T}_{0}$ as a function of different applied magnetic field, the obtained results were gathered in fig. 6. One can notice that $\mathrm{T}_{0}$ decreases in a parabolic shape with increasing magnetic field, which is more significant for $\mu_{0} \mathrm{H} \geq 5 \mathrm{~T}$. This suggest that the application of $7 \mathrm{~T}$ field starts to affect the CO state. In the case of $\mathrm{Dy}^{3+}$ ions, $8 \mathrm{~T}$ field was enough to collapse the CO-AFM state at $5 \mathrm{~K}$ in the case of $\mathrm{La}_{0.4} \mathrm{Dy}_{0.1} \mathrm{Ca}_{0.5} \mathrm{MnO}_{3}[23]$.

The evolution of MR isotherms as a function of the applied magnetic field for $\mathrm{La}_{0.45} \mathrm{Ho}_{0.05} \mathrm{Ca}_{0.5} \mathrm{MnO}_{3}$ sample is shown in fig. 7. The MR values below $1 \mathrm{~T}$ are close to $0 \%$, which indicates the absence of low-field MR. For higher field values, MR increases and the increase is more important for lower temperature values due to the presence of magnetic ordering. The existence of long-range CO is responsible for the low MR values (-MR $\approx 20 \%$ at $130 \mathrm{~K}$ under $7 \mathrm{~T}$ field). The evolution of $\mathrm{MR}(\mathrm{H})$ curves can be described by the following relation [30]:

$$
-M R\left(\mu_{0} H\right)=\frac{K \times H^{p}}{H_{L}^{p}+H^{p}}+\frac{(100-K) \times H^{q}}{H_{H}^{q}+H^{q}}(8)
$$

where $\mathrm{K}$ is the amplitude of low-field MR, $\mathrm{p}$ and $\mathrm{q}$ are critical exponents characterizing the low-field and high-field MR, respectively and $\mu_{0} \mathrm{H}_{\mathrm{L}}$ and $\mu_{0} \mathrm{H}_{\mathrm{H}}$ are critical field values 
characterizing the low-field and high-field MR, respectively. We have indicated the absence of low-field MR for our sample in the studied temperature range, which means that $\mathrm{K}$ parameter should be fixed to zero. Thus, relation (8) can be written as:

$$
-M R=\frac{100 \times H^{q}}{H_{H}^{q}+H^{q}}(9)
$$

The fitted curves are gathered in fig .8 and the fitting parameters for our sample by using relation (9) are summarized in table 3. According to the results of table 3, one can observe that q values are close to 2 . The values of $\mu_{0} \mathrm{H}_{\mathrm{H}}$ (theoretical field value required to achieve $-\mathrm{MR}=$ $50 \%$ ) increase with increasing temperature due to the temperature induced reduction of magnetic ordering.

\section{Conclusion}

In this paper, the electrical and magnetotransport response of $\mathrm{La}_{0.5-\mathrm{x}} \mathrm{Ho}_{\mathrm{x}} \mathrm{Ca}_{0.5} \mathrm{MnO}_{3}(\mathrm{x}=$ 0.05 and 0.1) samples have been investigated. All Ho doped samples exhibit an insulating behavior in the whole studied temperature range, with high resistivity values, confirming the establishment of long-range CO state. The temperature dependent resistivity follows VRH model. With increasing magnetic field up to $7 \mathrm{~T}$, no remarkable change can be detected, which gives an idea about the strength of CO state. This fact indicates that Ho substitution stabilizes the CO state charactering the parent compound $\mathrm{La}_{0.5} \mathrm{Ca}_{0.5} \mathrm{MnO}_{3}$.

\section{Declarations}

Funding The authors received no specific funding for this work.

Conflicts of interest/Competing interests The authors confirm that there are no known conflicts of interest associated with this publication and there has been no significant support for this work that could have influenced its outcome.

Availability of data and material The data that support the findings of this study are available from the corresponding author upon reasonable request.

\section{References}

[1] A. Krichene, W. Boujelben, S. Mukherjee, N.A. Shah, P.S. Solanki, Ceram. Int. 45, 3849 (2019) 
[2] S. Dhieb, A. Krichene, N. Chniba Boudjada, W. Boujelben, J. Phys. Chem. C, 32, 17762 (2020)

[3] P. Amirzadeh, H. Ahmadvand, P. Kameli, B. Aslibeiki, H. Salamati, A.G. Gamzatov, A.M. Aliev, I.K. Kamilov, J. Appl. Phys. 113, 123904 (2013)

[4] A. Krichene, P.S. Solanki, D. Venkateshwarlu, S. Rayaprol, V. Ganesan, W. Boujelben, D.G. Kuberkar, J. Magn. Magn. Mater. 381, 470 (2015)

[5] E. Dagotto, T. Hotta, A. Moreo,

Phys. Rep. 344, 1 (2001)

[6] S. Dhieb, A. Krichene, N. Chniba Boudjada, W. Boujelben, J. Alloy. Compd. 823, 153728 (2020)

[7] V.P.S. Awana, R. Tripathi, S. Balamurugan, A. Kumar, A. Dogra, H. Kishan, J. Alloy. Compd. 475, L13 (2009)

[8] A. Antonakos, E. Liarokapis, G.H. Aydogdu, H.U. Habermeier, J. Magn. Magn. Mater. 323, $620(2011)$

[9] M. Bourouina, A. Krichene, N. Chniba Boudjada, W. Boujelben, Ceram. Int. 43, 8139 (2017)

[10] A. Krichene, W. Boujelben, A. Cheikhrouhou, J. Alloy. Compd. 581, 352 (2013)

[11] P.E. Schiffer, A.P. Ramirez, W. Bao, S.W. Cheong, Phys. Rev. Lett. 75, 3336 (1995)

[12] A. Krichene, W. Boujelben, A. Cheikhrouhou, J. Alloy. Compd. 550, 75 (2013)

[13] R.S. Freitas, L. Ghivelder, Phys. Rev. B. 65, 104403 (2002)

[14] H. D. Zhou, G. Li, S. J. Feng, Y. Liu, T. Qian, X. J. Fan, X. G. Li, Solid State Commun. 122, 507 (2002)

[15] X. G. Li, R. K. Zheng, G. Li1, H. D. Zhou, R. X. Huang, J. Q. Xie, Z. D. Wang, Europhys. Lett. 60, 670 (2002)

[16] A. Krichene, P.S. Solanki, D. Venkateshwarlu, S. Royaprol, V.Ganesan, W. Boujelben, D.G. Kberkar, J. Magn. Magn. Mater. 381, 470 (2015) 
[17] A. Krichene, W. Boujelben, S. Mukherjee, N.A. Shah, P.S. Solanki, Phys. Chem. Chem. Phys. 20, 12608 (2018)

[18] A. Krichene, W. Boujelben, J. supracond. Nov. Magn. 31, 577 (2018)

[19] A. Krichene, W. Boujelben, A. Cheikhrouhou, EPJ Web Conf. 29, 00045 (2012)

[20] A. Krichene, W. Boujelben, K.N. Rathod, K. Gadani, N.A. Shah, P.S. Solanki, Ceram. Int. 46, 8010 (2020)

[21] A. Krichene, W. Boujelben, K.N. Rathod, K. Gadani, N.A. Shah, P.S. Solanki, J. Electron. Mater. 49, 5244 (2020)

[22] A. Krichene, W. Boujelben, S. Mukherjee, N.A. Shah, P.S. Solanki, J. Phys. Chem. Solids 14, 21 (2018)

[23] A. Krichene, W. Boujelben, S. Mukherjee, P.S. Solanki, N.A. Shah, Acta Mater. 131, 491 (2017)

[24] R.R Doshi, P.S. Solanki, Uma Khachar, D.G. Kuberkar, P.S.R. Krishna, A. Banerjee, P. Chaddah, Physica. B 406, 4031 (2011)

[25] I. Dhiman, A. Dasa, P. K. Mishra, N. P. Lalla, A. Kumar, J. Magn. Magn. Mater. 323 (2011) 748 .

[26] G.K. Williamson, W.H. Hall, Acta Metall. 1, 22 (1952)

[27] T. Terai, T. Sasaki, T. Kakeshita, T. Fukuda, and T. Saburi, Phys. Rev. B. 61, 5 (2000)

[28] D. Sousa, M.R. Nunes, C. Silveira, I. Matos, A.B. Lopes, M.E. Melo Jorge, Mater. Chem. Phys. 109, 311 (2008)

[29] N.F. Mott, Philos. Mag. 19, 835 (1969)

[30] A. Krichene, W. Boujelben, N.A. Shah, P.S. Solanki, J. Alloys Compd. 820, 153400 (2018) 


\section{Table captions}

Table 1: Structural parameters of $\mathrm{La}_{0.5-\mathrm{x}} \mathrm{Ho}_{\mathrm{x}} \mathrm{Ca}_{0.5} \mathrm{MnO}_{3}(\mathrm{x}=0.05$ and 0.1 ) samples.

Table 2: Fitting parameters of $0 \mathrm{~T}$ field resistivity for $\mathrm{La}_{0.5-\mathrm{x}} \mathrm{Ho}_{\mathrm{x}} \mathrm{Ca}_{0.5} \mathrm{MnO}_{3}(\mathrm{x}=0.05$ and 0.1$)$ samples.

Table 3: Fitting parameters of the magnetic field dependence of MR by using relation (9) for $\mathrm{La}_{0.45} \mathrm{Ho}_{0.05} \mathrm{Ca}_{0.5} \mathrm{MnO}_{3}$ sample.

\section{Figure Captions}

Fig. 1: Rietveld refinement of the $\mathrm{XRD}$ patterns for the $\mathrm{La}_{0.5-\mathrm{x}} \mathrm{Ho}_{\mathrm{x}} \mathrm{Ca}_{0.5} \mathrm{MnO}_{3}(\mathrm{x}=0.05$ and 0.1$)$ samples.

Fig. 2: Williamson-Hall plots of $\mathrm{La}_{0.5-\mathrm{x}} \mathrm{Ho}_{\mathrm{x}} \mathrm{Ca}_{0.5} \mathrm{MnO}_{3}(\mathrm{x}=0.05$ and 0.1$)$ samples.

Fig. 3: SEM images of $\mathrm{La}_{0.5-\mathrm{x}} \mathrm{Ho}_{\mathrm{x}} \mathrm{Ca}_{0.5} \mathrm{MnO}_{3}(\mathrm{x}=0.05,0.1$ and 0.15$)$ samples.

Fig. 4: Temperature dependence of electrical resistivity under several values of applied magnetic field for $\mathrm{La}_{0.5-\mathrm{x}} \mathrm{Ho}_{\mathrm{x}} \mathrm{Ca}_{0.5} \mathrm{MnO}_{3}(\mathrm{x}=0.05$ and 0.1$)$ samples.

Fig. 5: Fit of high-temperature electrical resistivity data using TA, SPH and VRH models for $\mathrm{La}_{0.5-\mathrm{x}} \mathrm{Ho}_{\mathrm{x}} \mathrm{Ca}_{0.5} \mathrm{MnO}_{3}(\mathrm{x}=0.05$ and 0.1$)$ samples.

Fig. 6: Evolution of Mott temperature as a function of applied magnetic field for $\mathrm{La}_{0.45} \mathrm{Ho}_{0.05} \mathrm{Ca}_{0.5} \mathrm{MnO}_{3}$ sample. The solid line shows the parabolic fit.

Fig. 7: Magnetic field dependence of isothermal MR for $\mathrm{La}_{0.45} \mathrm{Ho}_{0.05} \mathrm{Ca}_{0.5} \mathrm{MnO}_{3}$ sample.

Fig. 8: Magnetic field dependence of $M R$ for several values of temperature for $\mathrm{La}_{0.45} \mathrm{Ho}_{0.05} \mathrm{Ca}_{0.5} \mathrm{MnO}_{3}$ sample. The solid line represent the fitting curves. 